\title{
Four Hazelnut Pollenizers Resistant to Eastern Filbert Blight
}

\author{
Shawn A. Mehlenbacher ${ }^{1}$ and Maxine M. Thompson ${ }^{2}$ \\ Department of Horticulture, Oregon State University, Corvallis, \\ $O R \quad 97331$
}

Additional index words. Corylus avellana, Anisogramma anomala, filbert. disease resistance, tree breeding

Eastern filbert blight, caused by the fungus Anisogramma anomala (Peck) E. Muller, is native to the eastern United States where the wild species Corylus americana Marsh. serves as its host. The disease is believed to have been introduced to the Pacific Northwest on nursery stock imported from the East Coast in the early 1960s. The disease is now firmly established in the northern third of the Willamette Valley, the major growing area, and is a serious threat to commercial acreage of the European hazel, Corylus avellana L. The life cycle of the fungus was described by Gottwald and Cameron (1980). Symptoms include perennial cankers that enlarge 30 to $100 \mathrm{~cm} \cdot y_{e a r}^{-1}$ and can exceed $2 \mathrm{~m}$ in length, girdling scaffold limbs and the tree trunk. The canopy of older trees of susceptible cultivars is killed in 7 to 10 years.

The most common hazelnut orchards in Oregon are planted to 'Barcelona', with 'Daviana' pollenizers planted every third tree in every third row. 'Barcelona' is considered tolerant of the disease, as infected trees remain productive for several years before eventually dying. 'Daviana', however, is highly susceptible. As eastern filbert blight spreads from one orchard to another, it is generally found first in the 'Daviana' pollenizers. From there, it spreads to the surrounding 'Barcelona' trees. 'Butler', the second most common pollenizer, is also highly susceptible. 'Hall's Giant' is considered tolerant and is currently recommended as a pollenizer for 'Barcelona', although it sheds pollen later than the ideal time. 'Gasaway', which is highly resistant to the disease (Mehlenbacher and Thompson, 1991), sheds its pollen very late in the season and, thus, is a poor choice as a pollenizer for 'Barcelona'. By replacing the highly susceptible pollenizers in a 'Barcelona' orchard with resistant genotypes, it should be possible to delay the time of initial infection and to maintain an infected orchard in a productive state for many years. Four resistant pollenizer selections were

Received for publication 24 May 1990. Oregon Agricultural Experiment Station Technical Paper no. 9249. This research was funded by the Oregon Hazelnut Commission. We acknowledge the assistance of personnel at the Southwest Washington Experiment Station. The cost of publishing this paper was defrayed in part by the payment of page charges. Under postal regulations, this paper therefore must be hereby marked advertisement solely to indicate this fact.

'Assistant Professor.

${ }^{2}$ Professor Emeritus. recently released by the Oregon Agricultural Experiment Station. Resistant pollenizers are viewed as one component in an integrated disease management program.

\section{Origin}

The four pollenizer selections resulted from crosses made by M.M.T. in 1976. VR4-31 and VR11-27 resulted from a cross of 'Montebello' x 'Gasaway'. VR20-11 resulted from a cross of OSU10-68, a 'Barcelona' $x$ 'Compton' hybrid, and 'Gasaway'. VR23-18 resulted from a cross of OSU13-19, a 'Barcelona' $\times$ 'Lansing' hybrid, and 'Gasaway'. Seedlings were planted at the Southwest Washington Experiment Station, Vancouver, and observed for symptoms of eastern filbert blight. When crossed with susceptible parents, 'Gasaway' transmits resistance to $50 \%$ of its progeny (Mehlenbacher and Thompson, 1991). The trees of these four selections have remained totally free of eastern filbert blight for 12 years, even though they were surrounded by infected trees and abundant inoculum throughout this period. Scions were cut from the selected trees, grafted onto rootstock, and grown in an iso-

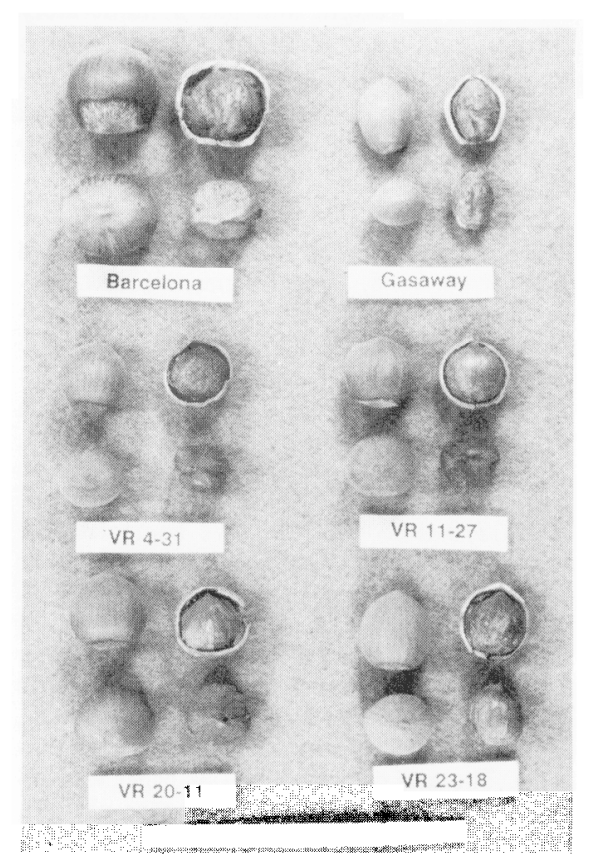

Fig. 1. Nuts and unblanched kernels of 'Barcelona', 'Gasaway', and four hazelnut pollenizer selections resistant to eastern filbert blight. 
Table 1. Description of 'Barcelona', 'Gasaway', and four pollenizer filbert selections.'

\begin{tabular}{lcccccc}
\hline Sclection & $\begin{array}{c}\text { Big bud } \\
\text { mites } \\
\text { (rating) }\end{array}$ & $\begin{array}{c}\text { Husk } \\
\text { length } \\
\text { (relative) }\end{array}$ & $\begin{array}{c}\text { Nut wt } \\
(\mathrm{g})\end{array}$ & $\begin{array}{c}\text { Kernel } \\
(\%)\end{array}$ & $\begin{array}{c}\text { Kernel } \\
\text { fiber } \\
\text { (rating) }\end{array}$ & $\begin{array}{c}\text { Blanch } \\
\text { (rating) }\end{array}$ \\
\hline Barcclona & 1 & 4 & 3.8 & 44 & 3 & 5 \\
Gasaway & 1 & 2 & 1.5 & 47 & 3 & 7 \\
VR 4-31 & 3 & 3 & 2.0 & 5.1 & 4 & 7 \\
VR 11-27 & 2 & 4 & 2.3 & 46 & 4 & 7 \\
VR 20-11 & 2 & 3 & 2.3 & 51 & 2 & 7 \\
VR 23-18 & 3 & 3 & 2.2 & 51 & 4 & 7 \\
\hline
\end{tabular}

${ }^{2}$ Big bud mite ratings arc from 1 (highly resistant) to 5 (highly susceptible). Husk length relative to nut length ranges from 2 (husk half as long as nut) to 6 (husk 50\% longer than nut). Percent kernel is the ratio of kernel weight to nut weight. Fiber ratings are from 1 (no fiber on pellicle) to 4 (heavy fiber). Blanch ratings reflect the extent of pellicle removal by dry heat $(130 \mathrm{C})$ for $14 \mathrm{~min}$ and range from 1 for complete removal to 7 for no removal.

lated greenhouse for two growing seasons before distribution to nurseries.

\section{Description}

VR4-31, VR11-27, VR20-11, and VR23-18 were released because of their value as pollenizers for 'Barcelona', rather than the value of their nuts. Trees of all four selections set an average number of catkins, which produce large quantities of viable pollen. Pollen of all four selections has been used in controlled crosses with excellent nut set. The four selections shed pollen at different times, but all overlap the time of receptivity of female flowers of 'Barcelona'. VR11-27, the earliest, sheds pollen at about the same time as 'Butler'. VR4-31 and VR2011 shed their pollen in midseason at roughly the same time as 'Daviana'. VR23-18 sheds its pollen in late midseason, almost as late as 'Hall's Giant' but well ahead of 'Gasaway'.

Although pollen of all four selections is compatible on stigmas of 'Barcelona', only VR20-11 will set nuts when pollenized by 'Barcelona'. VR20-11 has incompatibility alleles $S_{2}$ and $S_{3}$, the same as 'Butler'. The other three selections have incompatibility alleles $\mathrm{S}_{1}$ and $\mathrm{S}_{3}$. Both $\mathrm{S}$-alleles are expressed in the stigmas, but, because of dominance, only $\mathrm{S}_{3}$ is expressed in the pollen of the four selections (Mehlenbacher and Thompson, 1988). VR4-31, VR11-27, and VR23-18 are compatible pollenizers for 'Barcelona', but the reciprocal cross is incompatible because $S_{1}$ is expressed in 'Barcelona' pollen. This unidirectional incompatibility is not a serious problem because the nuts of the pollenizers are of poor quality.

Nut and husk descriptions (Table 1) are based on observations of the original seedling. trees. Predation by birds was a serious problem, except in 1988, when all trees were netted. VR4-31 and VR11-27 have consistently had light crops. VR20-11 has had intermediate crop loads, while VR23-18 has had intermediate to heavy crop loads. It is unlikely that any would outyield 'Barcelona'. Nuts of all four selections are small and fall free of the husk at maturity. Nuts of VR4-31 and VR20-11 are nearly round, while those of VR11-27 and VR23-18 are slightly long and compressed (Fig. 1). Kernels of VR20-11 have a trace of fiber on the pellicle, while those of the other three selections are heavily fibrous. The pellicle and attached fiber are not removed by blanching.

VR4-31 and VR23-18 exhibit an intermediate reaction to big bud mites (primarily Phytoptus avellanae Nal.). VR11-27 and VR20-11 are considered resistant, although a few galled buds can be found upon close examination. Chemical control of this pest will be unnecessary in most situations.

\section{Availability}

These four pollenizers are released as a public germplasm with no restrictions. Grafted trees are available from several Oregon nurseries. Layered trees will be available after 1991. A list of nurseries propagating these selections is available from S.A.M.

\section{Literature Cited}

Gottwald, T.R. and H.R. Cameron. 1980. Infection site, infection period, and latent period of canker caused by Anisogramma anomala in European filbert. Phytopathology 70:1083-1087.

Mehlenbacher, S.A. and M.M. Thompson. 1988. Dominance relationships among S-alleles in Corylus avellana L. Theor. Appl. Genet. 76:669672.

Mehlenbacher, S.A. and M.M. Thompson. 1991. Occurrence and inheritance of resistance to eastern filbert blight in 'Gasaway' hazelnut. HortScience 26:410-411. 